\title{
AN EXPERIMENTAL INVESTIGATION OF THE THERMAL/FLUID PROPERTIES OF THE NITRATE TO AMMONIA AND CERAMIC (NAC) PRODUCT SLURRY
}

I. Muguercia, L. Lagos, G. Yang, W. Li, and M. A. Ebadian ${ }^{2}$

Department of Mechanical Engineering

Florida International University

Miami, FL 33199

(305) 348-2569

\section{ABSTRACT}

Experimental tests are conducted to measure the apparent viscosity, the pressure drop, and the heat transfer coefficient of the pipe flow of the Nitrate to Ammonia and Ceramic (NAC) process product slurry. The tests indicate that the NAC product slurry exhibits a typical pseudoplastic fluid behavior. The pressure drop in the pipe flow is a function of the Reynolds number and the slurry temperature. The results also indicate that at a low slurry temperature, the slurry is uniformly heated peripherally. At a high slurry temperature, however, the slurry may be thermally stratified. In a straight pipe, the Nusselt number is reduced as the slürry temperature increases.

\section{INTRODUCTION}

As regulation of the waste decontamination process becomes increasingly restrictive, one of the major challenges worldwide is the safe storage of liquid nuclear waste. Over the past 50 years, millions of tons of low-level radioactive waste (LLW) have been generated at various U.S. weapons facilities. This LLW is temporarily stored at U.S. Department of Energy facilities, such as

\author{
A. J. Mattus, D. D. Lee, J. W. Walker, \\ and R. D. Hunt \\ Chemical Technology Division \\ Oak Ridge National Laboratory \\ Oak Ridge, TN 37831-6273 \\ (615) 576-1795
}

the single-shell tanks at the Hanford site, the Savannah River site, the Melton Valley Storage Tanks at Oak Ridge National Laboratory, and the Pad A Waste site at Idaho Falls, where it is held for final disposal. Preliminary studies indicate that more than $60 \%$ of the chemical concentration in the liquid waste is composed of sodium nitrate with a radiation level of 0.1 to $1.2 \mathrm{R} / \mathrm{h}$. The characteristics of this sodium nitrate-based waste, in addition to the levels of radioactivity, are as follows: $\mathrm{pH}$, either $<1$ or $>12$, with a total salt content of $>5 M$ and a sodium content of $>1.5 \mathrm{M}$. Radioactive waste in the liquid state poses a great threat due to the potential for seepage into groundwater supplies. Therefore, it must be immobilized before final disposal. Currently, the most common immobilization method for LLW is the use of cement-based grout. Unfortunately, nitrate anions and sodium cations are very mobile and difficult to immobilize, especially in relatively porous, cement-based grout. Another long-term disposal method, such as biodenitrification, is only in its early developing stage.

Recently, a new immobilization technique for LLW, the Nitrate to Ammonia and Ceramic (NAC) process, has been developed. ${ }^{1}$ Instead of mixing the liquid waste form directly

${ }^{2}$ Corresponding author.

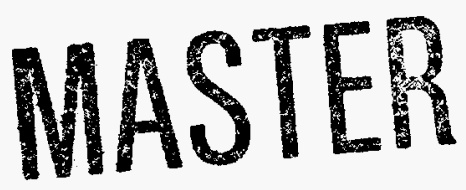




\section{DISCLAIMER}

Portions of this document may be illegible in electronic image products. Images are produced from the best available original document. 
with the cement to make concrete blocks, the NAC process eliminates the nitrate from the LLW by converting it to ammonia gas. Aluminum particles are used as a reductant to complete this conversion. The final product of the NAC process is gibbsite, which can be further sintered to a ceramic waste form. Preliminary tests have indicated that the NAC process not only produces environmentally acceptable waste, but can also reduce the volume of the final waste by up to $70 \%$, as compared with the cement-based grout. This volume reduction represents a significant reduction in cost for final land disposal. The NAC process is an exothermic process, which generates large amounts of heat during the chemical reaction. In order to maintain a desired operating temperature of between 50 and $85^{\circ} \mathrm{C}$ inside the NAC reactor, a cooling system is required. By considering the initial cost and convenience of operation and maintenance, an external heat exchanger has been selected for cooling the prototype NAC process facility. ${ }^{2}$ To design a cooling system and the heat exchanger, one needs to know the flow and thermal behaviors of the product slurry. Unfortunately, this information is not available in the open literature.

In order to maintain the properties of the slurry at a constant level, nonradioactive slurry, similar to the final product of the NAC, is used to simulate the actual slurry. Preliminary tests indicate that the NAC product slurry exhibits a typical pseudoplastic fluid (one type of non-Newtonian fluid) behavior. Because non-Newtonian fluids have more complicated relations between the shear stresses and the velocity field, additional factors must be considered in examining various fluid mechanics and heat transfer phenomena. ${ }^{3}$ Knowledge of non-Newtonian fluid mechanics and heat transfer is still in an early stage, and at present, some information can be obtained only by experimental study. Thus, the objective of this study is to experimentally determine these fluid flow and thermal behaviors.

\section{THE TEST FACILITY}

A test facility has been designed and constructed for measurement of the rheological properties and the heat transfer coefficient of the pipe flow. Figure 1 illustrates the test facility, which consists of a NAC process reactor, the test loop, and associated instrumentation. The NAC reactor is a 6-L chemical reactor (model BioFlo IIC manufactured by New Brunswick Scientific), which can automatically control the flow rate, the temperature, and the $\mathrm{pH}$ value of the fluid. The reactor operates in a continuous mode $^{4}$ and can continuously provide the slurry with the same rheological/thermal properties. The slurry product is pumped from the reactor to a test loop and then discharged back to the reactor. The slurry product is pumped from the reactor to a test loop and then discharged back to the reactor. The slurry flow rate is measured by a magnetic flowmeter (Endress \& House, Inc.) with an uncertainty of less than $\pm 1 \%$. The test loop is constructed of a 1 -in.diameter stainless steel pipe. The test loop has two test sections: the heating section and the temperature control section. The 8-ft-long heating section is used to measure the heat transfer coefficient of the slurry pipe flow. Six flat rope heaters, which can provide $3 \mathrm{KW}$, are wrapped around the outside of the pipe, and the test section is insulated with fiberglass packing. Three Variacs are used to control the heating power. Thermocouples and pressure transducers are installed at both the inlet and outlet of this section. In order to determine the wall temperature, 40 thermocouples are also installed along the test section. The thermocouples and the pressure transducers are connected to a HewlettPackard data acquisition system and are continuously monitored by a personal computer during the test. The uncertainty of the thermocouples is less than $\pm 0.2^{\circ} \mathrm{C}$, and the uncertainty of the pressure measurement is less than $\pm 0.5 \%$. The 8-ft-long temperature control section is a double-pipe heat exchanger, which is used to provide the 
desired slurry temperature in the reactor. A digitally controlled chiller is used to regulate the outlet slurry temperature. Two methods have been used to measure the rheological properties of the slurry: direct measurement by an on-line viscometer and calculation of the measured information of the pressure drop and flow rate through the pipe. A Cambridge piston-style viscometer, model N4S550, is used for the on-line viscosity measurement. The uncertainty of this viscometer is $\pm 1.5 \%$ of the value read.

\section{RESULTS AND DISCUSSION}

\section{A. Rheological Properties of the Slurry}

The slurry looked like white paint when the gibbsite concentration was about $20 \%$ by weight, and no settling of solid particles took place during the test. The viscometer was used to measure the slurry's apparent viscosity at different velocities. The water viscosity was measured first to calibrate the viscometer. The slurry velocity varied from 0.7 to $7 \mathrm{~m} / \mathrm{s}$. Figure 2 shows the apparent viscosity as a function of the shear rate. The shear rate is defined by

$$
\gamma=8 u_{m} / d,
$$

where $u_{m}$ and $d$ are the slurry mean velocity and the pipe diameter, respectively. The apparent viscosity was read directly from the on-line viscometer, while the mean velocity of the slurry was calculated from the corresponding flow rate from the magnetic flowmeter. It was obvious that the gibbsite slurry was a type of pseudoplastic fluid; that is, the apparent viscosity decreased as the shear rate increased. Therefore, a power law model can be used to present the flow behavior of the gibbsite slurry:

$$
\tau=\mathrm{K} \boldsymbol{\gamma}^{\mathrm{n}}
$$

and

$$
\mu=\mathrm{K} \gamma^{\mathrm{n}-1}
$$

Figure 2 indicates that at a low temperature, $\mathrm{T}=30^{\circ} \mathrm{C}$, the apparent viscosity varies from 22 centipoise at $\gamma=35001 / \mathrm{s}$ to 9 centipoise at $\gamma=11,0001 / \mathrm{s}$. At a high temperature, $\mathrm{T}=70^{\circ} \mathrm{C}$, the apparent viscosity of the slurry is almost half the value of that at the low temperature. The flow behavior index, $\mathrm{n}$, which is a measure of the non-Newtonian character of the slurry, is approximately 0.3 , which is not sensitive to the fluid temperature, as mentioned in previous studies. ${ }^{3}$ After establishing a suitable rheological model for the gibbsite slurry, the next stage of the investigation was to investigate the pressure drop in the pipe flow.

\section{B. Pressure Drop in the Pipe Flow}

The pressure difference in the pipe flow was measured by a pressure transducer. Figure 3 shows the measured pressure drop in a 2.83-m-long straight pipe. The Reynolds number is calculated by

$$
\operatorname{Re}=\left(\rho u_{m}^{2-n}\right) / K,
$$

where $\rho$ is the slurry density. The figure indicates that the pressure drop in the pipe flow is not only a function of the Reynolds number, but is also sensitive to the slurry temperature. As the Reynolds number increased, the pressure drop increased. At a high temperature, the pressure drop was much lower than that at the low temperature, which was expected, since the slurry apparent viscosity reduced with the temperature. For example, the pressure drop for the $30^{\circ} \mathrm{C}$ slurry was almost double compared with the case of the slurry at $70^{\circ} \mathrm{C}$, which coincides with the finding in Fig. 2. 


\section{Heat Transfer in the Pipe Flow}

Water was tested first to ensure that the thermocouples, the electric heater, and the wall insulation were in good condition. Figure 4 illustrates that the wall and the fluid bulk temperatures varied with the pipe location. In the figure, the dark circles and the open circles represent the readings of thermocouples on the top and bottom of the pipe, respectively. The figure indicates that the thermocouples were working well. The mean Nusselt number, calculated based on the test data, is 62.09. With the same flow parameters, the prediction by Incropera and DeWitt, ${ }^{5}$

$$
\mathrm{Nu}=0.027 \operatorname{Re}^{0.8} \operatorname{Pr}^{0.33}\left(\mu / \mu_{\mathrm{s}}\right),
$$

is 56.7. Our test data are around $10 \%$ higher than the prediction by Eq. (5), since the test was conducted in the entry region, while Eq. (5) is valid only for the fully developed region.

Figure 5 illustrates the temperature distribution along the test section of the pipe for the slurry test. The solid line indicates the slurry bulk temperature, while the dark and open circles indicate the temperatures on the top and bottom walls of the pipe. The slurry flow rate is $18.1 \mathrm{~L} / \mathrm{min}$, with the gibbsite concentration $20 \%$ by weight. : Figure $5 \mathrm{a}$ indicates the test result with the slurry temperature at approximately $40^{\circ} \mathrm{C}$. It can be seen that the wall temperatures of both the top and bottom walls are close to each other, which means that the wall is uniform peripherally. As the slurry temperature reaches $60^{\circ} \mathrm{C}$, the temperatures of the top wall and the bottom wall grow apart, as seen in Fig. 5b. This phenomenon becomes more visible as the slurry temperature reaches $90^{\circ} \mathrm{C}$, which indicates that the fluid may be stratified thermally, and natural convective heat transfer also becomes important.
Figure 6 shows that the mean Nusselt number varied with the slurry bulk temperature. In this figure, the flow rate of the slurry was kept at $18.1 \mathrm{~L} / \mathrm{min}$, with a solids concentration of $20 \%$ by weight. The figure indicates that as the slurry bulk temperature increased, the Nusselt number decreased. Actually, this phenomenon can also be observed in Fig. 5. With the same energy input, the logarithm mean temperature difference between the slurry and the solid wall is around $7^{\circ} \mathrm{C}$, while it reaches $18^{\circ} \mathrm{C}$ when the slurry temperature is around $90^{\circ} \mathrm{C}$.

\section{SUMMARY}

An experimental measurement of the rheological properties and heat transfer rate of the NAC product slurry in pipe flow has been conducted. Nonradioactive slurry, similar to the final product of the NAC process, was used to simulate the actual slurry. The test results indicate that the NAC product slurry exhibits a typical pseudoplastic fluid behavior; that is, the apparent viscosity reduced as the shear rate increased. The results also indicate that the pressure drop along the pipe is a function of the flow Reynolds number, as well as the slurry temperature. When the temperature was reduced from 70 to $30^{\circ} \mathrm{C}$, the pressure drop almost doubled. When heat was applied to the pipe, the results indicate that the wall temperature was uniform peripherally at a low slurry temperature. However, at a high slurry temperature, the temperature on the top-half wall was around $15^{\circ}$ higher than that of the bottom-half wall, which suggests the existence of thermal stratification of the slurry. Finally, the test results indicate that the Nusselt number decreased with a slurry bulk temperature increase. 


\section{ACKNOWLEDGMENT}

These results were obtained in the course of research sponsored by the U.S. Department of Energy Office of Technology Development under grant no. 19X-SN855C.

\section{NOMENCLATURE}

d pipe diameter, $\mathrm{m}$

$\mathrm{K}$ fluid consistency, $\mathrm{N} \mathrm{s}^{3-\mathrm{n}} / \mathrm{m}^{2}$

$\mathrm{Nu} \quad$ Nusselt number

Pr Prandtl number

Re Reynolds number

$\mathrm{T}$ temperature, ${ }^{\circ} \mathrm{C}$

$u_{m} \quad$ slurry mean velocity, $m / s$

Greek Symbols

$\gamma \quad$ shear rate, $1 / \mathrm{s}$

$\mu$ apparent viscosity, $\mathrm{Ns} / \mathrm{m}^{2}$

$\rho \quad$ slurry density, $\mathrm{kg} / \mathrm{m}^{3}$

$\tau$ shear stress, $\mathrm{N} / \mathrm{m}^{2}$

Superscript

n flow index

Subscript

s surface

\section{REFERENCES}

1. A. J. Mattus and D. D. Lee, "The Nitrate to Ammonia and Ceramic (NAC) Process - A Newly Developed Low Temperature Technology," Second International Mixed Waste Symposium, Aug. 17-20, 1993, Baltimore, Maryland, 1993.

2. E. L. Youngblood, Jr., personal communication, February 1993.

3. T. F. Irvine and J. Karni, "Non-Newtonian Fluid Flow and Heat Transfer," Chapter 20 of the Handbook of Single Phase Convective Heat Transfer, ed. by S. Kakac, R. K. Shah, and W. Aung, Wiley Interscience, New York (1987).

4. A. J. Mattus, D. D. Lee, T. A. Dillon, E. L. Youngblood, T. Tiegs, and L. L. Farr, "A Low Temperature Process for the Denitration of the Hanford Single Shell Tank, Nitrate-Based Waste Utilizing the Nitrate to Ammonia and Ceramic (NAC) Process, Phase II Report," a report to the U.S. Department of Energy, DE-AC0584OR21400, Oak Ridge National Laboratory (1993).

5. F. P. Incropera and D. P. DeWitt, Introduction to Heat Transfer, 2nd ed., John Wiley \& Sons, Inc., New York (1990).

\title{
DISCLAIMER
}

\begin{abstract}
This report was prepared as an account of work sponsored by an agency of the United States Government. Neither the United States Government nor any agency thereof, nor any of their employees, makes any warranty, express or implied, or assumes any legal liability or responsibility for the accuracy, completeness, or usefulness of any information, apparatus, product, or process disclosed, or represents that its use would not infringe privately owned rights. Reference herein to any specific commercial product, process, or service by trade name, trademark, manufacturer, or otherwise does not necessarily constitute or imply its endorsement, recommendation, or favoring by the United States Government or any agency thereof. The views and opinions of authors expressed herein do not necessarily state or reflect those of the United States Government or any agency thereof.
\end{abstract}



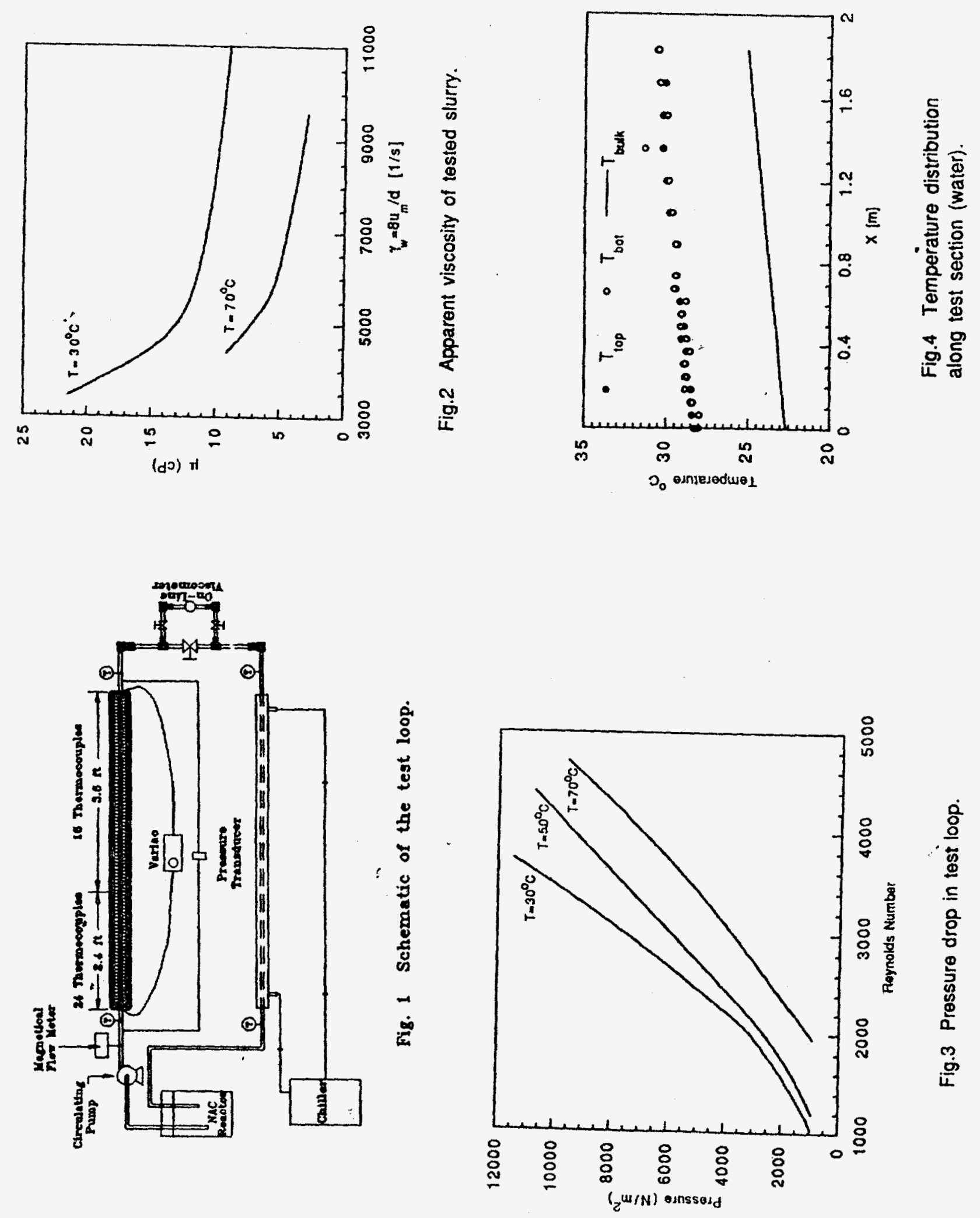


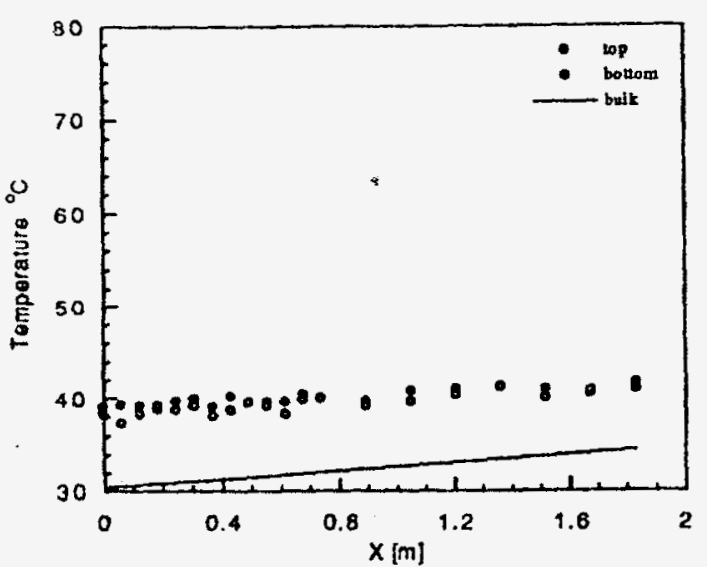

a)

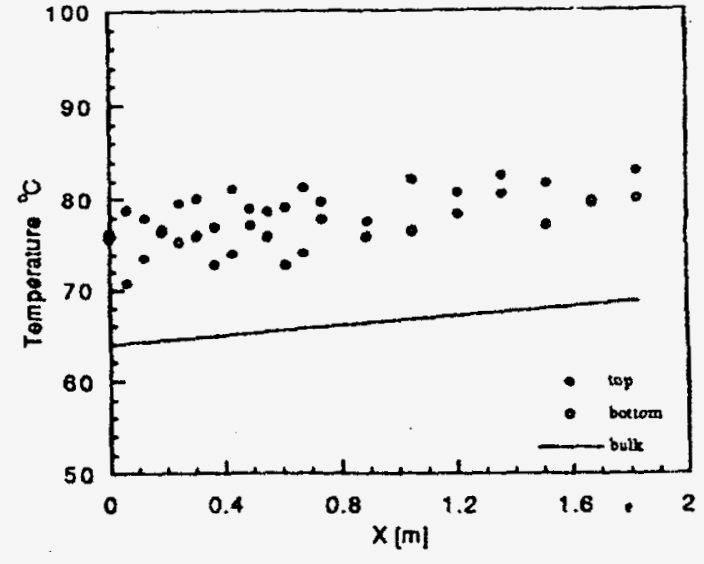

b)

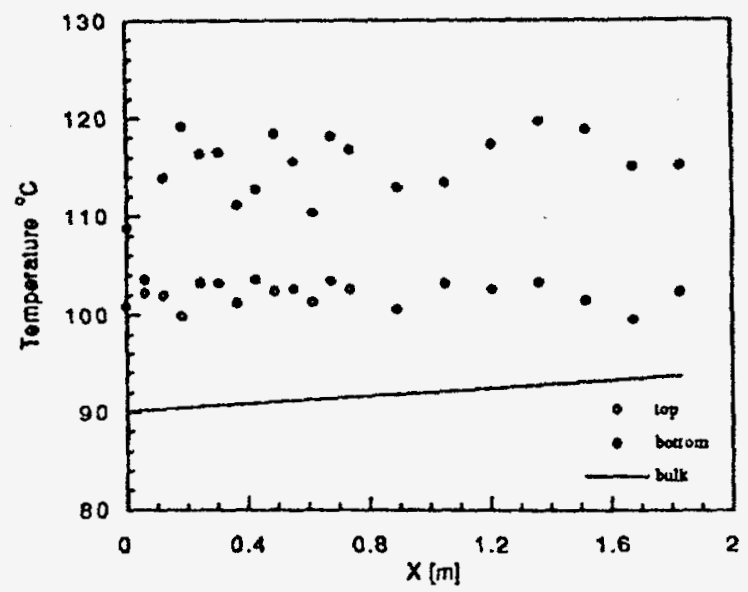

c)

Fig.5 Temperature distribution along the test section (Slurry).

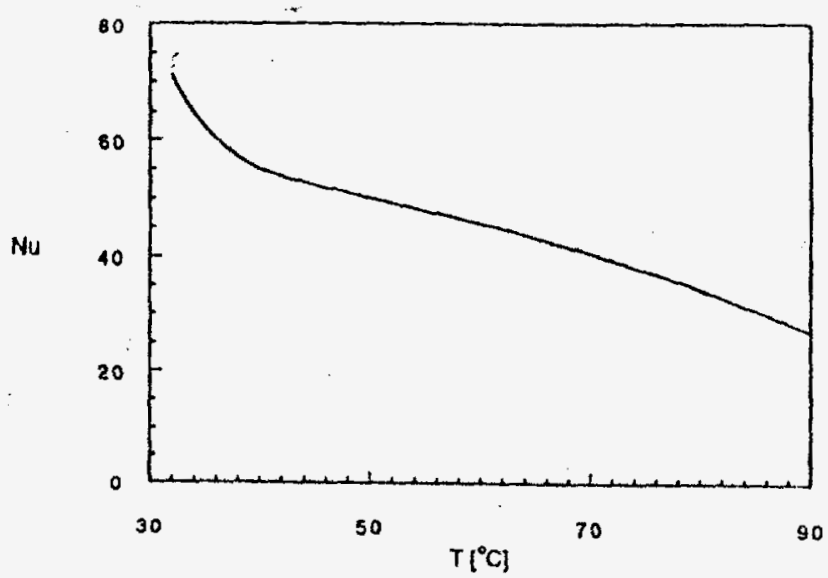

Fig.6 Nussett as a function of slurry temperature. 